\title{
Expertise in ill-defined problem-solving domains as effective strategy use
}

\author{
CHRISTIAN D. SCHUNN, MARK U. MCGREGOR, and LELYN D. SANER \\ University of Pittsburgh, Pittsburgh, Pennsylvania
}

\begin{abstract}
Expertise consists of many different cognitive structures. Lemaire and Siegler (1995) have proposed a four-layered account of expertise from a strategies perspective: Experts have better strategies, tend to use strategies that are better overall more often, are better able to select the circumstances to which a strategy best applies, and are better able to execute a given strategy. Originally, this account came from work in simple, well-defined domains. We explored this account in the complex, ill-defined domain of platoon leadership. In Experiment 1A, we elicited free-text responses to leadership scenarios from novices, intermediates, and experts, finding expertise effects for strategy base rates and choice, but not for strategy existence or the number of strategies used. In Experiment 1B, we used a new group of experts to gather ratings of the execution accuracy of the responses in Experiment $1 \mathrm{~A}$ and found expertise differences in the ability to execute the same strategies. We propose several elaborations to the original four-layered strategies account of expertise on the basis of these results.
\end{abstract}

What is the nature of expertise in complex domains? The research literature has shown that experts have acquired a variety of cognitive structures that contribute to their high levels of performance (for summaries, see Ericsson, 1996; Feltovich, Ford, \& Hoffman, 1997; Sternberg \& Grigorenko, 2003). Candidate cognitive structures include greater familiarity with those aspects of situations that facilitate memory (Gobet \& Simon, 1996), better representations that capture the more important features of the domain (Chi, Feltovich, \& Glaser, 1981), access to previous solutions (Logan, 1988), and well-practiced component skills (Ericsson, Krampe, \& Tesch-Römer, 1993). One general perspective on expertise that we will explore is the strategies perspective, which can include a variety of the different cognitive structures underlying expertise, but organized together in a way that allows for layered predictions.

The most basic instantiation of the strategies perspective is that experts have better strategies than do novices and that this difference in strategy existence explains why experts' performance is higher than that of novices. Here, a strategy is defined as a coherent set of steps for solving a problem in a context in which different coherent sets of steps are possible. For example, older children have a min strategy for adding two numbers (count up from the larger of the two numbers by the smaller amount), whereas younger children use a less sophisticated count-all strategy, and that strategy

This work was supported by Grant DASW01-00-K-0017 from the U.S. Army Research Institute and Grant N00014-01-1-0321 from the U.S. Office of Naval Research to the first author. We thank Laura Poms, Cedric Yeo, Darcie Kunder, and Celestine Cookson for their help in collecting and coding the data. Correspondence concerning this article should be addressed to C. D. Schunn, Learning Research and Development Center, University of Pittsburgh, 3939 O'Hara St., Pittsburgh, PA 15260 (e-mail: schunn@pitt.edu). difference explains, in part, why older children add numbers more quickly (Siegler \& Jenkins, 1989).

Although this basic strategy difference seems quite plausible and parsimonious, it has been shown to be incomplete in research done by Siegler and others in the late 1980s and early 1990s. In particular, in a wide variety of domains, it became clear that every individual possesses multiple strategies at every point in time and that one cannot describe learning or development as the transition from the predominant use of a worse strategy to the predominant use of a better strategy. Instead, learning is more clearly the change from one mixture of strategies to another mixture of strategies (see Siegler, 1996, for a review).

What did this new conception of strategy use imply for expertise? Lemaire and Siegler (1995) proposed a fourlayered conceptual model, called the adaptive strategy model (ASM) for those aspects of strategies that might differ with expertise. The four layers are strategy existence, strategy base rate, strategy choice, and strategy execution.

On the basis of the strategy existence dimension, one can predict that experts will have some useful strategies that novices do not, although experts and novices will have many strategies in common (Lee \& Anderson, 2001; Schraagen, 1993; Schunn \& Anderson, 1999; Voss, Tyler, $\&$ Yengo, 1983). For example, studies of the learning of addition have shown that older children (experts) use a retrieval strategy and younger children (novices) rely on a calculate strategy (Siegler, 1988); expert air traffic controllers are more likely to use a workload management strategy than are novice air traffic controllers (Seamster, Redding, Cannon, Ryder, \& Purcell, 1993).

The strategy choice dimension posits that experts will be better able to choose the circumstances under which particular strategies should be applied (Schunn, Reder, Nhouyvanisvong, Richards, \& Stroffolino, 1997; Siegler 
\& Lemaire, 1997). For example, with serial recall tasks, older children (experts) have been shown to choose a repeated rehearsal strategy more often than do younger children (novices), who also knew the strategy and would have benefited from choosing to use the rehearsal strategy (McGilly \& Siegler, 1990).

On the basis of the strategy base rate dimension, one would predict that experts will know which strategies are generally more effective and will tend to select those strategies (Lovett \& Anderson, 1996; Lovett \& Schunn, 1999; Schunn \& Reder, 1998). For example, in a simple problem-solving task, Lovett and Anderson found that novices learned that one strategy was generally more appropriate than other strategies through experience and began to select that strategy more often overall. Thorndike's (1913) law of effect is essentially the same principle. Note that strategy choice refers to selecting strategies on the basis of features of the situation, whereas strategy base rates refer to selecting strategies not because of the features of the situation, but because of gross overall success patterns across previous experiences.

On the basis of the strategy execution dimension, one would predict that when experts and novices use the same strategy, the experts will use common or shared strategies more quickly and more effectively than will novices (Delaney, Reder, Staszewski, \& Ritter, 1998; Lee \& Anderson, 2001; Lovett \& Anderson, 1996; Rickard, 1997). For example, Delaney et al. (1998) found that students became faster at executing mental addition algorithms through repeated practice, even when trials on which they had retrieved the answer were excluded.

Lemaire and Siegler (1995) validated this overall conceptual model in the domain of the solving of multiplication problems by second graders. They found evidence of differences with expertise in strategy base rates, strategy choice, and strategy execution. They did not find evidence for strategy existence improvements, but the cases in the literature of strategy existence differences led them to assume that the overall four-layer model was useful.

No further work with ASM has been done in studies of expertise, but many important theoretical questions remain. First, what are the relative time courses of the four different layers? Lemaire and Siegler (1995) found no strategy existence differences in their data set. Does that imply that strategy existence differences often apply only at the very earliest stages of development? Assuming that all four kinds of learning are taking place at the same time, with no differential bias or emphasis in the cognitive system, one would logically expect the following.

1. Strategy execution differences should build up gradually and continuously with experience. Work by Delaney et al. (1998), Rickard (1997), and others suggests that speed up with practice is due not only to transitions in strategies from compute to retrieve, but also to gradual improvements in the speed of both compute and retrieve actions themselves.

2. Strategy base-rate differences should occur before strategy choice differences, because strategy choice learning requires exposure to a broad set of situations, whereas the strategy base rates can be learned from a smaller (but representative) set of situations. On the other hand, suppose that there was no base-rate learning per se and that any observed base-rate effects were, in fact, just the result of strategy choice learning. In that case, base-rate differences would seem to emerge slowly and subsequent to strategy choice learning.

3 . The relative ordering of strategy existence differences with respect to the other changes is unclear. It may be that strategies are discovered first and then the other forms of strategy learning take place. Alternatively, it may be that new, more effective strategies are developed only once a better understanding of a domain had been developed (Siegler \& Crowley, 1994).

This issue of complexity of the domain brings up a second open question about the ASM and expertise: Does the four-layered strategies account apply to more complex domains, especially domains involving the solving of illdefined problems (domains in which the set of possible actions is very open, rather than constrained to a previously determined set, and solutions are not obviously just correct or incorrect)? For example, perhaps one cannot find the clustering of behavior that describes the expert and the novice because the problem solution paths are too open. Alternatively, expertise may more strongly consist of retrieving (and possibly adapting) solutions to past problems, as has been suggested by some (Forbus, Gentner, \& Law, 1995; Gobet \& Simon, 1996; Logan, 1988).

Finally, the ASM framing of the strategy existence question may be too narrow. Rather than wondering just about strategy growth, one may wonder about strategy growth and strategy winnowing together. Do experts have more strategies than novices do, or do they perhaps use only a smaller, more effective set of strategies? Work by Alibali and by Siegler suggests that there may be an inverted U-shaped function in which people move through a transitional state in which they use more strategies but then settle on a smaller set of strategies (Alibali \& Goldin-Meadow, 1993; Siegler, 1994, 1996). That work was also done on relatively simple mathematics problem solving. It is unclear that such transitional states will apply to the much more lengthy time course of learning that occurs in the development of expertise in complex, ill-defined problem-solving domains. Moreover, in a simple domain, the set of possible choices of strategies may be relatively constrained, and thus novices may tend to start by using a small set of strategies and then grow a couple of overlooked strategies, until settling on using the best set of strategies. By contrast, in a complex, ill-defined domain, the set of possible strategies may seem overwhelmingly large to the novice, and the whole process of developing expertise may consist of winnowing away unhelpful strategies.

In this article, we attempt to address these open issues about strategy accounts of expertise in the context of an extremely complex, ill-defined problem-solving domain: platoon leadership.

\section{Leadership}

Leadership is a prime example of an ill-defined domain; there are almost as many definitions of leadership as there 
are persons who have attempted to define the concept (Stogdill, 1981). We define leadership as the process of interpersonal influence in which direct and indirect means are employed to get others to accomplish the organization's goals, where influence is achieved by providing purpose, direction, and motivation (Horvath et al., 1999). This definition is the definition utilized by the U.S. Army, which has one of the most comprehensive leadership-training programs in the world (Horvath et al., 1999).

There are also many levels of leadership within the U.S. Army (from commanding 10 to commanding 100,000), each of which demands different skills and behaviors. This study focused on the platoon level of leadership, which is the most direct level of leadership (Horvath et al., 1999). Direct-level leadership is characterized by face-toface interactions with small groups (20-40 individuals), in contrast to middle-level (organizational) or high-level (strategic) leadership (e.g., battalion, division, or corps), where the group sizes are in the hundreds to thousands of individuals, and the amount of leader-follower interaction is quite small (Hunt, 1991).

A large percentage of past research on leadership has come from a personality psychology and selection perspective (e.g., Gardner, 1989; Mann, 1959; Stogdill, 1948), especially more recent work (Borman \& Brush, 1993; Fleishman et al., 1991; Lord, De Vader, \& Alliger, 1986). For example, individual differences across multiple personality traits are often cited as significant factors in determining effective leadership (Stogdill, 1981). In another large percentage of the research on leadership, an attempt has been made to decompose the skills required for leadership. For example, the leadership literature makes a big distinction between direction setting and operational management (Katz \& Kahn, 1978; Yukl, 2002). Finally, part of the leadership literature has sought to characterize the behaviors associated with effective leadership (Engle \& Lord, 1997; Hackman \& Walton, 1986; Hooijberg \& Schneider, 2001; Liden, Wayne, \& Stilwell, 1993). At some level, one might equate those behaviors as strategies (House \& Shamir, 1993; Shamir, Zakay, Breinin, \& Popper, 1998). But on the whole, the strategies approach has not been previously applied to the understanding of expertise in leadership; certainly, strategy factors other than strategy existence have not been applied to unpacking expertise in leadership.

We present a two-part experiment examining expertnovice differences in leadership across the four components of the ASM. In Experiment 1A, we examined the existence, choice, and base-rate components; in Experiment $1 \mathrm{~B}$, we examined the execution component.

\section{EXPERIMENT 1A}

The primary goal of Experiment 1A was to examine relative group differences in strategy existence, choice, and base rate, as well as to look for strategy growth and winnowing. We developed 50 leadership scenariossituations that a platoon leader is likely to encounter in the field. We used these scenarios to collect open-ended, free- text responses from three different groups: novices, intermediates, and experts. We then coded these responses into categories of general leadership strategies. Once the responses were coded into their underlying strategies, we analyzed the different patterns of strategy usage in the three groups.

\section{Participants \\ Experts. Sixty-six U.S. Army lieutenants and captains from two} Army bases participated voluntarily. All the experts had commanded a platoon within the last 5 years.

Intermediates. Twenty-three undergraduates enrolled in the Reserve Officer Training Corps (ROTC) program at George Mason University (GMU) were recruited through the ROTC office at GMU. Intermediates received payment for their participation at a rate of $\$ 10 / \mathrm{h}$.

Novices. Thirty-nine undergraduates from the University of Pittsburgh with no military experience participated for course credit.

\section{Materials}

Leadership scenarios. Leadership scenarios represented situations that a platoon leader is likely to encounter in everyday practice. They were not tactical battle scenarios requiring multilayered, elaborate responses. Instead, they were more local problem-solving scenarios that typically require a single response. Fifty leadership scenarios were developed using two U.S. Army resources. First, 15 scenarios were taken directly from the Tacit Knowledge for Military Leaders: Platoon Leader Questionnaire (TKML: PLQ), a recently developed military leadership assessment tool. Second, the head of the GMU ROTC program helped researchers adapt another 35 scenarios taken from the Army Leadership Tacit Knowledge Corpus (ALTKC), a collection of Army leaders' self-reported leadership experiences. The resulting 50 scenarios covered the main competencies commonly associated with platoon leadership (Horvath et al., 1999; see Table 1).

Each scenario was designed to require a single strategy, rather than a combination of different strategies within one response. Note that the scenarios contained no military acronyms or other components that might make the scenarios impenetrable to the nonexperts. Here is an example scenario:

Your platoon is going to be deployed for a very long period of time. One of your soldiers requests to stay behind to be with a child who has a life-threatening illness. His position is integral to the mission. How do you respond to his request?

To make the amount of work required of the participants manageable, the 50 scenarios were divided into five subsets of 10 scenarios each (subsets were balanced for competency type), and each participant generated free-text responses to one set (10 responses). Set and scenario order within set were randomly assigned. The scenarios were presented 1 per page, with considerable space for a response. Each response was assumed to reflect the instantiation of a particu-

Table 1

Platoon Leader Competencies and Number of Scenarios Relating to Each Competency

\begin{tabular}{lc}
\hline Platoon Leader Competency & Number of Scenarios \\
\hline Teaching and counseling & 10 \\
Soldier team development & 11 \\
Supervision & 9 \\
Communication & 8 \\
Planning & 4 \\
Decision making & 4 \\
Use of available systems & 4 \\
\hline
\end{tabular}


lar leadership strategy, and these responses were the primary source of data for this study.

Leadership strategies. Strategy categories were developed to reflect the general kinds of responses that one could, in theory, apply across a wide range of situations but were also specific enough to reflect the core intent of particular responses. Because the leadership literature is heavily focused on the personality and social psychology levels of analysis and on very general styles of leadership, such as transactional versus transformational leadership, we developed our own categorization scheme. Leadership strategies were developed by two raters performing a card sort on a corpus of responses (between 5 and 10 responses per problem) to the 15 problems in the TKML: PLQ. This card sort produced 14 initial categories or strategies. After a preliminary coding of additional responses, it became clear that coders were consistently confusing certain strategies. An analysis of a confusability matrix of coders' disagreements identified overlapping strategies, which were then combined, resulting in 10 distinct strategies. The head of the GMU ROTC program also helped to clarify these strategy definitions. The 10 leadership strategies and brief descriptions are listed in Table 2, and their full definitions are included as the Appendix. Table 3 shows three different responses to the same scenario, and each response is an example of a different strategy. Note that the definitions of these leadership strategies are quite general and could be applied to other areas of leadership.

\section{Procedure}

For the nonexperts, all the experimental materials were presented in the lab via a World-Wide Web browser on a computer networked to a Web server. The expert participants lacked outside network access on the bases and received paper-and-pencil versions of the same tasks. All the participants received as much time as necessary to complete the tasks. The participants were asked to provide a detailed description of how they would handle each given scenario, and there were no limits on the length of their responses.

\section{Data Coding}

Strategy use. The primary source of data in Experiment 1 was the participants' open-ended responses to leadership scenarios. The participants typically spent $3-5$ min generating a response to each of 10 scenarios, and responses were approximately 80 words long, on average.

Three raters categorized each response as an implementation of 1 of 10 leadership strategies, using the strategy definitions and the open-ended responses with their corresponding scenario (for context). The raters were blind as to the source of any individual response (novice, intermediate, or expert). If a rater felt that more than one strategy description could apply to a response, he or she identified which strategy was the most dominant.

The raters coded subsets of responses individually and then compared ratings and, after a lengthy training process, obtained a reliability of $85 \%$ agreement (measured on an untrained $15 \%$ of the data, drawn equally from the three participant types, with raters blind as to source). Then all three raters coded the full corpus, and discrepancies were resolved through discussion.

Ideal response strategies. The assessments of strategy existence, strategy choice accuracy, and strategy base-rate improvements depend on a valid measure of the correctness of answers to our scenarios (at the strategy level). Unfortunately, ill-defined domains, such as leadership, do not come with logically correct answers, as math problems do. Yet, for any particular ill-defined problem, there is usually a consensus among experts that one particular answer is better or more ideal than others. We determined, accordingly, an ideal response strategy for each of our 50 scenarios, using an expert consensus approach. In particular, we used the consensus across the 66 experts in Experiment 1A. An ideal response for each scenario was defined in terms of the experts' modal response strategy for that scenario. In the seven cases in which the modal strategy was a tie, we counted both strategy responses as an ideal. Figure 1 shows a histogram of ideal strategy use across the
Table 2 Leadership Strategies and Brief Descriptions

\begin{tabular}{|c|c|}
\hline Strategy & Brief Description \\
\hline Authoritative & Give direct commands without justification. \\
\hline Avoidance & $\begin{array}{l}\text { No immediate action; assume the situation } \\
\text { will resolve itself. }\end{array}$ \\
\hline Influencing & $\begin{array}{l}\text { Convince or persuade others of your point } \\
\text { of view. }\end{array}$ \\
\hline Planned action & $\begin{array}{l}\text { Careful, deliberate, and rational planning } \\
\text { of actions. }\end{array}$ \\
\hline Proactive & $\begin{array}{l}\text { Do not wait for instruction, act on antici- } \\
\text { pation of solutions. }\end{array}$ \\
\hline Professional development & $\begin{array}{l}\text { Focus on personal development and self- } \\
\text { management while maintaining military } \\
\text { bearing, give feedback to improve per- } \\
\text { formance, solicit soldiers' opinions and } \\
\text { suggestions. }\end{array}$ \\
\hline Punishing & Immediately threaten punitive actions. \\
\hline Reinforcement & $\begin{array}{l}\text { Actively seek advice from others (superi- } \\
\text { ors, peers, friends, etc.). }\end{array}$ \\
\hline Seek information & $\begin{array}{l}\text { Seek additional information about the cur- } \\
\text { rent situation. }\end{array}$ \\
\hline Supportive & $\begin{array}{l}\text { Show compassion or empathy for soldiers' } \\
\text { perspectives, provide appropriate rewards } \\
\text { and recognition. }\end{array}$ \\
\hline
\end{tabular}

Note-See the Appendix for full definitions.

Table 3

One Scenario and Three Sample Response Strategies (With Type of Participant Producing the Sample in Parentheses)

\section{Scenario 37-Competency: Communication}

At National Training Center (NTC), your platoon has just completed a night move and you have been in position for two hours. A weapon is identified as missing around midnight. You know that the weapon is in this position because it was seen during the previous sensitive item check conducted as part of position improvement. Another sensitive item report is due at 0400 . How do you handle this situation?

\section{Proactive Response (Expert)}

\section{Response Strategies}

"Immediately, I will take the platoon and sweep the position for the missing weapon. I would also conduct hourly sensitive items checks hourly until 0400 hours."

\section{Authoritative Response (Intermediate)}

"Find the weapon, have a PCI of all sensitive items around the area, check everyone, until it was found. Nobody would go anywhere or go to sleep until it was found."

\section{Planned-Action Response (Novice)}

"I would go get the weapon and go look for it. I would alert the other officers what I was doing and I would go find that weapon if I knew where it was. After all I was just sitting around for 2 hours being useless so I might as well do something. Then I would get some members of my team to go ahead and start working on the sensitive time report so it could be ready in time. If it weren't ready I'd tell them that I was looking for the weapon."

50 scenarios. The mean proportion (across scenarios) of experts who responded with each modal strategy was $.46(S D=.17)$.

This approach to defining the ideal responses raises a potential circularity in our expert/novice comparisons, because we have guaranteed some similarity between expert and ideal choices. To address this issue, we had three levels of expertise. If the novices differ from the intermediates in the same ways as the intermediates differ from the experts, the results are clearly not the result of a definitional circularity. For example, if intermediates are significantly better on the choice 
measure than are novices, this result cannot be attributed to any problems involved in using expert choices to define the correct answers.

One alternative approach by which this circularity may be addressed is to use another method for defining ideals: use the solutions that were identified in the original sources of the scenarios. The advantage of this method is that it provided a fully independent definition of the correct response. The disadvantage is that the identified strategy may not be the best strategy for the given scenario, because we had to modify many of the scenarios from their original sources: Several scenarios from the TKML: PLQ had to be modified to fit an open-response format, rather than a rating-of-fixed-alternatives format; scenarios from the ALTKC sometimes had to be adapted from a company level of leadership to a platoon level; and sometimes different trade-offs exist at different levels of leadership to produce different ideal solutions. Moreover, the solutions for the ALTKC were described as good solutions that were actually tried, rather than as necessarily the best solutions. Thus, these ideals are likely to be only approximately ideal.

We decided to focus our analyses on the outcome of the first method for generating ideals, because it was more likely to be accurate. But it turned out that the two methods produced similar results. For example, the same four strategies were the most frequent under either method, in the same order of frequency. Because many of our analyses focused on these four strategies, we had similar results regardless of which ideals selection approach was used. In particular, the existence and base-rate analyses were then identical. The strategy execution analyses (found in Experiment 1B) did not depend on the method of ideals selection at all.

The only analysis that was affected by the approach to selecting ideals was that of strategy choice. Unfortunately, strategy choices analyses are also the ones most sensitive to getting the ideal definitions exactly correct, because strategy choice focuses on appropriateness of choice on a scenario-by-scenario basis. However, if our results were produced by the circularity, we would expect to find no differences between novices and intermediates.

\section{Results and Discussion}

\section{Strategy Existence}

Did experts know some strategies that nonexperts did not? If experts possess strategies that nonexperts lack, we should see this difference in the best strategies, those that were an ideal response across all 50 scenarios most frequently. The four most effective strategies were proactive, authoritative, planned action, and influencing, respectively (see Figure 1). The same four were most frequently ideals whether one looked at all 50 scenarios or only at the 25 scenarios on which the experts had the highest level of agreement.

Strategy existence was then measured by examining presence (i.e., the occurrence of the strategy for each participant anywhere within his or her 10 responses) for each of the top four strategies (see Table 4). Overall, we see no evidence of an increase in the existence of the top strategies with expertise, and if anything, the trend is in the opposite direction $[F(2,125)=1.2, p>.3]$. If one looks at each of the top four strategies separately, there is no hint of change for the proactive and authoritative strategies $(F \mathrm{~s}<1)$. The observed change for planned action is not significant $[F(2,125)=1.3, p>.25]$ and is not in the expected direction. The observed change for the influencing strategy is statistically significant $[F(2,125)=5.6, p<$ $.01]$ but, again, is not in the expected direction. In neither case do experts show the existence of more strategies than do novices or intermediates. Thus, we see no evidence for the discovery of new strategies with expertise but, rather, some evidence that the groups chose not to use a strategy that had been used by the groups at lower levels of expertise. In other words, growth in strategy existence appears not to be part of the expertise story in this domain.

\section{Strategy Growth or Winnowing}

Related to the question of strategy existence changes is the question of whether the total number of strategies used by the participants changes with expertise, either growing overall or winnowing. Table 5 presents the mean number of different strategies used by each participant in each

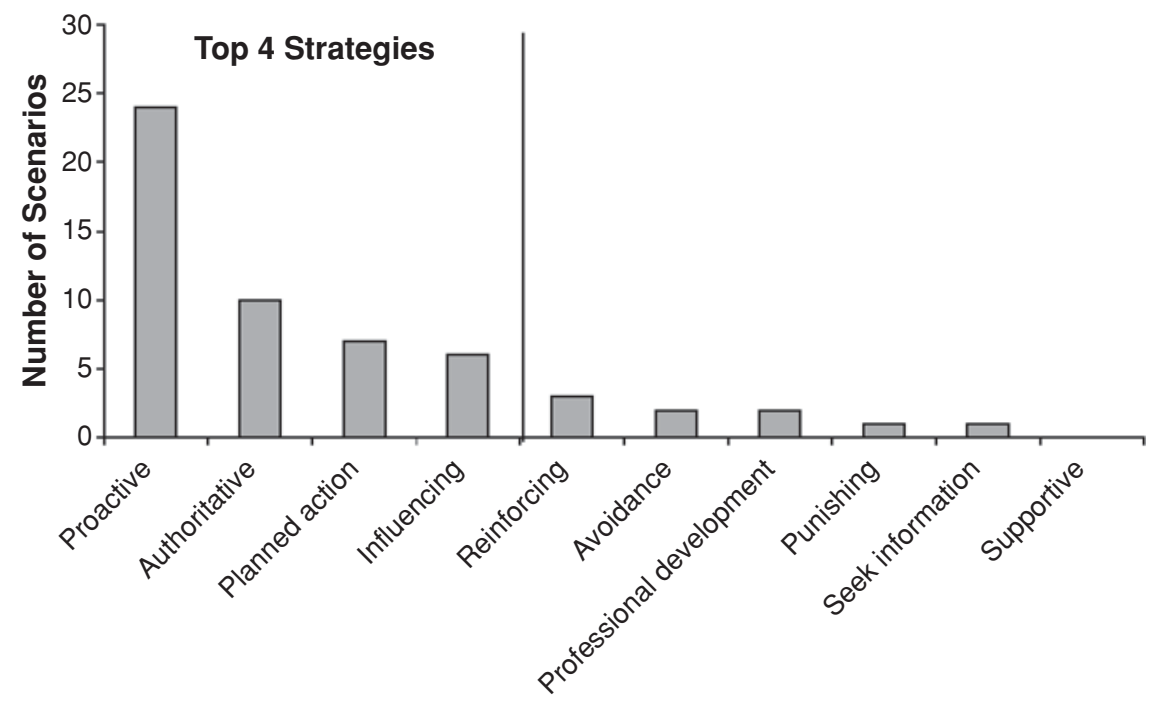

Figure 1. Number of scenarios for which each strategy was considered the ideal response to the scenario (across 50 scenarios), using the expert consensus method. 
Table 4

Mean Existence of Top Four Ideal Strategies Separately and All Combined, by Group

\begin{tabular}{|c|c|c|c|}
\hline Strategy & Novice & Intermediate & Expert \\
\hline 1. Proactive & .92 & .91 & .95 \\
\hline 2. Planned action & .74 & .57 & .73 \\
\hline 3. Authoritative & .79 & .78 & .82 \\
\hline 4. Influencing & .85 & .83 & .58 \\
\hline All combined & .44 & .26 & .32 \\
\hline
\end{tabular}

group. There was no change in the number of strategies used with expertise $[F(2,125)<1]$. Although null results are always problematic, the data do provide some bounds on how large true differences might be. In particular, the $95 \% \mathrm{CI}$ on the change from novice to expert is $[-0.4$, 0.8 ] strategies, or stated in terms of percentage of change, $[-7 \%, 14 \%]$. Thus, our results do tell us that this domain contains, at most, a very minor change of either overall strategy growth or strategy winnowing with increasing expertise, if at all.

\section{Strategy Choice}

Do experts choose strategies more appropriately than nonexperts do? For each of the top four strategies that an individual used at least once, we computed a vector of ones and zeros to represent each individual's pattern of strategy choices across the given 10 scenarios responded to $($ chosen $=1$, not chosen $=0)$. We then correlated that vector with the analogous vector for the ideal pattern of choices for the same strategy on the given set of 10 scenarios, including only the participants for a given strategy analysis for whom that strategy was used at least once (i.e., it appeared to exist in their strategy set). The advantage of this approach was that it removed possible differences in strategy existence and strategy base-rate effects from our analysis of strategy choice differences. We repeated this process with each participant for each of the top four strategies. We then examined group differences in appropriate choice accuracy by comparing mean group correlations. We used the top four strategies not because they were better strategies per se, but because they were chosen often enough by most participants to reliably measure choice patterns.

As was expected, we see a progression in the individuals' abilities to make appropriate strategy choices as they gain experience (see Table 5). Intermediates chose strategies more accurately than did novices $[t(198)=2.14, p<$ $.05]$, and experts chose strategies more accurately than did intermediates $[t(272)=2.57, p<.01]$. This pattern of improvement in strategy choice with expertise held true within each of the four strategies.

It is important to note that the difference in strategy choice accuracy between novices and intermediates is statistically significant and is just as large as the difference between experts and intermediates. This general trend across all three levels of expertise demonstrates that the observed expertise effects on strategy choice cannot be attributed to a circularity in our approach to deriving ideal choices for each scenario.

\section{Strategy Base Rate}

Did experts show a stronger overall preference than nonexperts did for generally more effective strategies? Each strategy's base rate was computed by counting the number of times it was an ideal response across all 50 scenarios, which approximates the overall probability of the strategy's being an effective solution to any platoon leadership scenario in general (see Figure 1). Individuals' base rates of strategy use were computed similarly for each strategy that an individual had in his or her repertoire (i.e., used once or more). Our analyses focused on the ordering of frequency of strategy use. If experts were more sensitive to strategy base rates, we would expect that experts would be more likely to order their frequency of strategy use to the ordering of ideals than would nonexperts. In other words, the experts should use the most effective strategy most often, the second most effective strategy second most often, and so on, whereas novices should use strategies in a manner less consistent with the same ideal order of strategy effectiveness. Again, we focused on the top four strategies because they occurred often enough to be observed reliably in most participants.

In conducting this analysis, we made one minor adjustment, for two reasons. First, the planned action and influencing strategies were ideal strategies close to equally often (seven and six times, respectively). Second, the majority of the participants used one but not both of these strategies, and we did not want to remove a majority of the participants from our analyses. Hence, we defined the ordering in a manner that treated the use of the planned action and influencing strategies as equal. The resulting

Table 5

For Each Expertise Group, Mean Number of Strategies per Participant, Mean Choice Accuracy Across the Top Four Ideal Strategies, Proportion of Participants Following BaseRate-Sensitive Ordering of the Top Four Ideal Strategies, and Mean Execution Quality (With Standard Errors for Each Measure)

\begin{tabular}{|c|c|c|c|c|c|c|}
\hline \multirow[b]{2}{*}{ Measure } & \multicolumn{2}{|c|}{ Novice } & \multicolumn{2}{|c|}{ Intermediate } & \multicolumn{2}{|c|}{ Expert } \\
\hline & $M$ & $S E$ & $M$ & $S E$ & $M$ & $S E$ \\
\hline Mean number of strategies per participant & 5.4 & 0.2 & 5.3 & 0.2 & 5.5 & 0.2 \\
\hline Mean choice accuracy & .14 & .03 & .26 & .04 & .39 & .03 \\
\hline Proportion following base-rate-sensitive ordering & .16 & .06 & .31 & .09 & .35 & .06 \\
\hline Mean execution quality & 5.7 & 0.2 & 6.0 & 0.2 & 6.2 & 0.2 \\
\hline
\end{tabular}


order was thus defined as using the proactive strategy more than the authoritative strategy $(1>2)$, and using the authoritative strategy more than either the planned action (3) or the influencing (4) strategy.

The mean proportion of the participants within each group who followed this maximally base-rate-sensitive ordering of strategy use is shown in Table 5. The experts were significantly more sensitive to the ordering by strategy base rates than were the novices $[t(103)=2.18, p<$ $.03]$, and the intermediates were nominally more sensitive to base-rate order than were the novices, although not significantly so $[t(60)=1.41, p<.16]$; there was no significant difference between the intermediates and the experts $(p>.7)$. Thus, we have an effect of expertise on base-rate sensitivity, but the noise levels are high relative to this effect, and the effect is statistically significant only when the extreme points are compared. It is worth noting, however, that these results cannot be attributed to a circularity in our approach to defining ideals for each scenario, because (1) the two approaches to defining the ideal produce identical effects in this analysis (because the two approaches produce the same ideal ordering against which participant responses are compared) and (2) the differences are larger in magnitude between novices and intermediates than between experts and novices, whereas the reverse would be true if the results were due to the circularity problem.

\section{Group Consistency Differences}

One might ask how consistent were the responses within each of the groups? Was it the case that the experts were simply more consistent with one another than the intermediates were and that the intermediates were more consistent with one another than the novices were? If expertise simply moved confusion toward a common understanding, one would expect such a reduction in within-group variability in strategy choice. However, it could be that novices come to the task with a particular set of common (mis)conceptions and that experience does not reduce variability but, rather, shifts what the general conceptions are. Such a result would be consistent with Siegler's (1996) claim that strategy variability is prevalent throughout performance.

One additional reason for examining this issue is that it might produce an alternative explanation for our group differences: If the increase in expertise had reduced withingroup variability and we defined correct performance by expert performance, one would expect increasing performance across our various strategy measures simply as a function of increased within-group consistency.

We examined the mean intercorrelations of strategy choices for each of the top four strategies (e.g., did each participant choose planned action on the same set of trials?). We found no group differences in these within-group intercorrelations, overall or within each of the top four strategies. The mean within-group intercorrelations were $.23, .17$, and .23 for the novice, intermediate, and expert groups, respectively. Thus, the data are consistent with Siegler's (1996) claims of the continued presence of strategy variability and does not support this alternative explanation of our groups' differences on the strategy use measures.

\section{EXPERIMENT 1B}

The purpose of Experiment 1B was to examine the fourth layer of the strategies perspective on expertise: expert-novice differences in the ability to execute or instantiate a strategy effectively. One might expect that experts would execute strategies more effectively than nonexperts, even when the same strategies were selected for the same scenarios. To examine this aspect, ratings were gathered from a new group of military experts to assess the execution quality of responses produced by each of the three groups in Experiment 1A.

Rather than having the experts rate all the responses from Experiment $1 \mathrm{~A}$, we had them rate a carefully selected subset of the total response set. The advantages of this approach are twofold. First, by having multiple raters rate a common set of items (which would not have been possible if different experts had rated different items in order to cover the full set of responses), we could examine consistency of rating and deal with confused or sloppy raters. Second, we did not want to confound execution with strategy choice or base rates, so we needed to find cases in which different expertise groups were using the same strategies and, thus, only execution could differ.

\section{Method}

\section{Participants}

Twenty-six U.S. Army lieutenants and captains from an army base (different from the two bases used in Experiment 1A) participated voluntarily. All the participants had commanded a platoon in the last 5 years.

\section{Materials}

Strategy execution abilities were assessed using a ratings task. For each of the three most frequently ideal strategies in Experiment 1A (proactive, authoritative, and planned action), we selected a set of prototypical responses from each group in Experiment 1A (54 items total). Each response was then combined with its corresponding scenario and strategy to produce ratings items. In order to gather ratings of responses independently of strategy choice, the participants were told that these responses had been produced by getting ROTC cadets to give the best possible implementation of a given strategy to the given scenario. Thus, they were to judge the effectiveness of implementation, not the effectiveness of strategy choice.

The 54 items were divided into two versions of the task, so that each participant evaluated 27 responses. Each set of 27 consisted of 3 responses from each of the three groups (novice, intermediate, and expert) for each of the three strategies (proactive, authoritative, and planned action). To the participants, it looked like 9 responses, all by ROTC cadets, for each of the three strategies. The order of items was blocked by strategy, but items from the different expertise groups were randomly distributed within those blocks. Responses were rated on a 9-point scale in terms of how effectively the given strategy was implemented in response to the given scenario ( 9 being best and 1 being worst).

\section{Procedure}

The participants were randomly assigned one of the two versions of the ratings task. Each version included overall text-based instructions that the researcher read out loud. The instructions emphasized that the task was to rate responses from real ROTC participants who 
had not been allowed to choose which strategy to use in generating their response to the given scenario. The participants were given as much time as needed to complete the task. Although time was not formally kept, it was informally observed that most of the participants completed the 27 items within $30 \mathrm{~min}$.

\section{Results and Discussion}

A few of the participants, feeling some time pressure to get back to work and/or having little interest in participating in this kind of research, appeared not to be fully motivated to participate. It should be also noted that this experiment was conducted during the early invasion period in 2003 of the Iraq war, and many soldiers had their minds focused on upcoming deployments. Moreover, as is always the case with Likert ratings tasks, some participants can confuse the direction of the ratings dimensions. To reduce the impact of low motivation or temporary confusion about the ratings dimensions, we examined the correlations of each participant's ratings with that of the group. We removed participants who were more than two standard deviations away from the mean correlation with average group judgments. This procedure removed 4 of the 26 participants from the remaining analysis. However, the same trends were observed in the removed participants as in the kept participants, just with much higher variance.

Each group's (novice, intermediate, and expert) strategy execution ability was measured by computing the mean expert rating of responses taken from that group (see Table 5). Ratings of strategy execution were significantly higher for expert than for novice responses $[t(22)=$ $2.80, p<.01]$ and for intermediate than novice responses $[t(22)=2.44, p<.05]$. The experts versus intermediates ratings were not statistically different $(p>.3)$, although the trend was in the expected direction.

\section{GENERAL DISCUSSION}

In this article, we examined the development of expertise in an ill-defined domain, leadership, in terms of a layered strategies account. Across Experiments 1A and 1B, expertise effects were found for three of the four layers: strategy choice, strategy base rate, and strategy execution. Interestingly, expertise differences were not found in terms of strategy existence.

These findings are interesting because they mirror exactly what was found by Lemaire and Siegler (1995) in their investigation of the four-layered strategy account of expertise in a much simpler, well-defined domain. Here, we will unpack the theoretical consequences of these findings.

\section{Supporting Strategy Accounts of Expertise}

First, we take the coherence of the results to lend some support in general to strategy decomposition approaches to expertise in ill-defined problem-solving domains - that is, that strategies are a useful theoretical tool for describing the elements of expertise, including expertise in illdefined problem-solving tasks. Perhaps it does not seem controversial to say that experts have a variety of procedures or approaches and that the strategic deployment of these procedures is an important part of their performance. On the other hand, most current accounts of expertise focus on cognitive elements other than strategies or procedures (e.g., chunks or representations), and there is some value in showing how much can be done within a strategies perspective in at least some domains. At the same time, it is worth noting that there are likely to be connections between strategies and chunks or representations (e.g., a retrieval strategy depends on the existence of chunks to be retrieved).

Do strategies really exist in the mind of the problem solver? One could argue that the organization of solutions into strategies lies within the mind of the researcher. In the case of platoon leadership, different solutions were grouped together into what we called strategies. Have we misrepresented the nature of expertise by grouping behaviors that are, at some level, quite different?

To begin with, it is important to acknowledge the hierarchical nature of strategies. In all situations but the simplest motor tasks, there are, in fact, multiple layers of strategies: One selects a general strategy or approach, and then there are different ways that general strategy or approach can be executed, which constitutes another level of strategy choice.

A diagnostic method for determining whether the posited strategies match what is in the mind of the problem solver is to ask the problem solver. In our case, we consulted with the head of an ROTC program about the definitions of our strategies. Moreover, in Experiment 1B, we gave our definitions to many experts to use, and they did not report confusion about these strategy definitions. In other studies not reported here, we have also given our definitions to ROTC cadets, and they were not confused by the definitions either. Thus, we have some confidence that the strategies we examined do correspond to the ways in which the problem solvers were thinking about the leadership scenarios.

\section{Elaborating the Strategies Account of Expertise}

A second implication of our results involves elaborations to the strategy view of expertise. For example, our results suggest that strategy existence differences may not be as important as other factors for some domains, at least over the range of expertise that we examined. As has already been noted, this particular finding mirrors the lack of strategy existence differences for those with expertise found by Lemaire and Siegler (1995), which was obtained in a very different setting. Given that most descriptions of expertise that mention the word strategy speak of strategy existence differences alone, this result will be important should it prove to be very general. It suggests that what other researchers have taken to be strategy existence differences may, in fact, simply be strategy choice or strategy base-rate differences. We do not wish to claim that strategy existence differences (typically referred to as the results of strategy discovery processes) are never part of expert/novice differences. In many settings, people learn 
new, more effective strategies (e.g., learning the min strategy in addition; Siegler \& Jenkins, 1989).

Another elaboration of the strategies account of expertise on the basis of our findings relates to the time course of the strategy layer changes. Contrary to what we predicted, strategy execution learning appears to be larger in the early stages of expertise than in later stages, since the differences between novices and intermediates was approximately twice as large as those between intermediates and experts. Although we expected continual improvement in strategy execution with practice, it may be that there are diminishing returns with increasing experience, as one would predict from a power law of learning. By contrast, strategy choice and strategy base rates saw approximately equal learning across the three levels of expertise that were examined. Overall, the observed time course in our data tentatively suggests the following order of strategy learning: (1) very early learning of new strategies, (2) large initial improvements in strategy execution, followed by slower growth in strategy execution quality, and (3) continual improvements in strategy base-rate and strategy choice accuracy. Considerable further research must be done to examine the generality of this proposed time course among the four layers of strategy expertise.

The third elaboration of the strategies account of expertise relates to the growth or winnowing of the overall number of strategies with expertise. Contrary to the previous findings from simpler, well-defined domains, such as elementary or middle-school math problem solving, we found no evidence for change in the total number of strategies used with increasing expertise or, at least, found that any such change must be relatively minor. It may be that complex, ill-defined domains always involve a variety of strategies, but only so many strategies can be effectively practiced. Alternatively, ill-defined domains may not have so many cases in which one strategy is clearly and logically more effective than other strategies, and so there is not as strong a push for strategy winnowing. Further research is required to determine whether other ill-defined domains will also have our observed pattern of no change in the number of strategies used.

\section{A New Theoretical Decomposition of Leadership Expertise}

Prior accounts of leadership have placed relatively little emphasis on cognitive structures and, certainly, little emphasis on cognitive structures within a learning framework. The present work shows that productive work can be done from a cognitive perspective in a complex social domain such as leadership. Moreover, nothing about our theoretical framework or set of identified strategy descriptions is logically specific to platoon leadership. Future work should examine expertise in other areas of leadership to see whether similar changes in effective strategy use with these same leadership strategies also accounts for expertise differences.

\section{Caveats}

There are several possible alternative explanations for our expert/novice differences in leadership. First, it may be that our results are attributable to a larger circularity in our approach to defining ideals. We did show that our results were not attributable to a direct circularity in using our own expert group data to define ideals for each scenario: The results for existence, base rate, and execution did not depend at all on the use of this approach, and the results for strategy choice were just as strong between novices and intermediates as between intermediates and experts. However, we have not provided an external validation of effective strategy use. That is, rather than showing that experts produced strategy choices that were actually better, we have established only that strategy choices were moving closer to U.S. Army experts' views of what good strategy use involves. Whether truly better performance or not was involved, we have demonstrated a variety of kinds of changes in behavior as a function of developing expertise.

Second, because we have partially confounded age with expertise (the intermediates and the novices were roughly the same age, but the experts were older), it is theoretically possible that some of our observed expertise differences (especially of the experts vs. the other two groups) are the result of maturation, rather than of domain-specific learning.

Third, it may be the case that representational differences determine strategy use differences. For example, perhaps experts represent more features of the problem that allow them to better make strategy choices. However, if training is the goal, focusing on internal representations may be inefficient. By focusing on how these strategies are used, it may be possible to strengthen or modify their underlying internal representation.

There are also three significant components of leadership expertise that were not addressed in this study. First, before any leadership action can be taken, a leader must recognize the need for it. Our scenarios presented situations as problems. Similarly, how an individual represents a problem situation will be an important determinant of how he or she solves it. We did not measure problem representation, at least not directly. Lastly, effective leadership requires the motivation to lead. Although recognition, representation, and motivation are all likely to be important components of leadership, they are separate loci of analysis and were not directly addressed in this study.

\section{REFERENCES}

Alibali, M. W., \& Goldin-Meadow, S. (1993). Gesture-speech mismatch and mechanisms of learning: What the hands reveal about a child's state of mind. Cognitive Psychology, 25, 468-523.

Borman, W. C., \& BRUSH, D. H. (1993). More progress toward a taxonomy of managerial performance requirements. Human Performance, 6, 1-21.

Chi, M. T. H., Feltovich, P. J., \& Glaser, R. (1981). Categorization and representation of physics problems by experts and novices. $\mathrm{Cog}$ nitive Science, 5, 121-152.

Delaney, P. F., Reder, L. M., Staszewski, J. J., \& Ritter, F. E. (1998). The strategy-specific nature of improvement: The power law applies by strategy within task. Psychological Science, 9, 1-7.

ENGLE, E. M., \& LORD, R. G. (1997). Implicit theories, self-schemas, and leader-member exchange. Academy of Management Journal, 40, 988-1010. 
ERICSSON, K. A. (ED.) (1996). The road to excellence: The acquisition of expert performance in the arts and sciences, sports, and games. Mahwah, NJ: Erlbaum.

Ericsson, K. A., Krampe, R. T., \& Tesch-Römer, C. (1993). The role of deliberate practice in the acquisition of expert performance. Psychological Review, 100, 363-406.

Feltovich, P. J., Ford, K. M., \& Hoffman, R. R. (Eds.) (1997). Expertise in context: Human and machine. Cambridge, MA: MIT Press.

Fleishman, E. A., Mumford, M. D., Zaccaro, S. J., Levin, K. Y., Korotkin, A. L., \& Hein, M. B. (1991). Taxonomic efforts in the description of leader behavior: A synthesis and functional interpretation. Leadership Quarterly, 2, 245-287.

Forbus, K. D., Gentner, D., \& LAw, K. (1995). MAC/FAC: A model of similarity-based retrieval. Cognitive Science, 19, 141-205.

Gardner, J. (1989). On leadership. New York: Free Press.

Gobet, F., \& Simon, H. A. (1996). Recall of random and distorted chess positions: Implications for the theory of expertise. Memory \& Cognition, 24, 493-503.

Hackman, J. R., \& Walton, R. E. (1986). Leading groups in organizations. In P. S. Goodman \& Associates (Eds.), Designing effective work groups (pp. 72-119). San Francisco: Jossey-Bass.

Hoomberg, R., \& Schneider, M. (2001). Behavioral complexity and social intelligence: How executive leaders use stakeholders to form a systems perspective. In S. J. Zaccaro \& R. Klimoski (Eds.), The nature of organizational leadership: Understanding the performance imperatives confronting today's leaders (pp. 104-131). San Francisco: Jossey-Bass.

Horvath, J. A., Forsythe, G. B., Bullis, R. C., Sweeney, P. J., Williams, W. M., McNally, J. A., ET Al. (1999). Experience, knowledge, and military leadership. In R. J. Sternberg \& J. A. Horvath (Eds.), Tacit knowledge in professional practice (pp. 39-57). Mahwah, NJ: Erlbaum.

House, R. J., \& Shamir, B. (1993). Towards the integration of transformational, charismatic, and visionary theories. In M. Chemers \& R. Ayman (Eds.), Leadership theory and research: Perspectives and directions (pp. 81-107). San Diego: Academic Press.

Hunt, J. G. (1991). Leadership: A new synthesis. Thousand Oaks, CA: Wiley.

Katz, D., \& KaHn, R. L. (1978). The social psychology of organizations. New York: Wiley.

LeE, F., \& Anderson, J. R. (2001). Does learning a complex task have to be so complex? A study in learning decomposition. Cognitive Psychology, 42, 267-316.

Lemaire, P., \& Siegler, R. S. (1995). Four aspects of strategic change: Contributions to children's learning of multiplication. Journal of Experimental Psychology: General, 124, 83-97.

Liden, R. C., Wayne, S. J., \& Stilwell, D. (1993). A longitudinal study on the early development of leader-member exchanges. Journal of Applied Psychology, 78, 662-674.

Logan, G. D. (1988). Toward an instance theory of automatization. Psychological Review, 95, 492-527.

Lord, R. G., De Vader, C. L., \& Alliger, G. M. (1986). A meta-analysis of the relation between personality traits and leadership perceptions: An application of validity generalization procedures. Journal of Applied Psychology, 71, 402-410.

Lovett, M. C., \& Anderson, J. R. (1996). History of success and current context in problem solving: Combined influences on operator selection. Cognitive Psychology, 31, 168-217.

LovetT, M. C., \& SchunN, C. D. (1999). Task representations, strategy variability and base-rate neglect. Journal of Experimental Psychology: General, 128, 107-130.

ManN, R. D. (1959). A review of the relationship between personality and performance in small groups. Psychological Bulletin, 66, 241-270.

MCGilly, K., \& Siegler, R. S. (1990). The influence of encoding and strategic knowledge on children's choices among serial recall strategies. Developmental Psychology, 26, 931-941.

RICKARD, T. (1997). Bending the power law: A CMPL theory of strategy shifts and the automatization of cognitive skills. Journal of Experimental Psychology: General, 126, 288-311.

SCHRAAGEN, J. M. (1993). How experts solve a novel problem in experimental design. Cognitive Science, 17, 285-309.

SCHUnN, C. D., \& ANDERson, J. R. (1999). The generality/specificity of expertise in scientific reasoning. Cognitive Science, 23, 337-370.

SchunN, C. D., \& Reder, L. M. (1998). Strategy adaptivity and individual differences. In D. L. Medin (Ed.), Psychology of learning and motivation (Vol. 38, pp. 115-154). New York: Academic Press

Schunn, C. D., Reder, L. M., Nhouyvanisvong, A., Richards, D. R., \& Stroffolino, P. J. (1997). To calculate or not to calculate: A source activation confusion model of problem familiarity's role in strategy selection. Journal of Experimental Psychology: Learning, Memory, \& Cognition, 23, 3-29.

Seamster, T. L., Redding, R. E., Cannon, J. R., Ryder, J. M., \& PurCELL, J. A. (1993). Cognitive task analysis of expertise in air traffic control. International Journal of Aviation Psychology, 3, 257-283.

Shamir, B., Zakay, E., Breinin, E., \& Popper, M. (1998). Correlates of charismatic leader behavior in military units: Subordinates' attitudes, unit of characteristics, and superiors' appraisals of leader performance. Academy of Management Journal, 41, 387-410.

SIEGLER, R. S. (1988). Strategy choice procedures and the development of multiplication skill. Journal of Experimental Psychology: General, 117, 258-275.

SIEGLER, R. S. (1994). Cognitive variability: A key to understanding cognitive development. Current Directions in Psychological Science, 3, 1-5.

SIEGLER, R. S. (1996). Emerging minds: The process of change in children's thinking. New York: Oxford University Press.

Siegler, R. S., \& Crowley, K. (1994). Constraints on learning in nonprivileged domains. Cognitive Psychology, 27, 194-227.

Siegler, R. S., \& Jenkins, E. A. (1989). How children discover new strategies. Hillsdale, NJ: Erlbaum.

Siegler, R. S., \& Lemaire, P. (1997). Older and younger adults'strategy choices in multiplication: Testing predictions of ASCM using the choice/no-choice method. Journal of Experimental Psychology: General, 126, 71-92.

SternberG, R. J., \& Grigorenko, E. L. (EDs.) (2003). The psychology of abilities, compentencies, and expertise. Cambridge: Cambridge University Press.

STOGDILL, R. M. (1948). Personal factors associated with leadership: A survey of the literature. Journal of Psychology, 25, 35-71.

Stogdill, R. M. (1981). Stogdill's handbook of leadership: A survey of theory and research. New York: Free Press.

ThorNDIKE, E. L. (1913). Educational psychology: Vol. 2. The psychology of learning. New York: Columbia University Teacher's College.

Voss, J. F., Tyler, S. W., \& Yengo, L. A. (1983). Individual differences in the solving of social science problems. In R. F. Dillon \& R. R. Schmeck (Eds.), Individual differences in cognition (Vol. 1, pp. 205-232). New York: Academic Press.

YuKL, G. (2002). Leadership in organizations (5th ed.). Englewood Cliffs, NJ: Prentice Hall. 


\section{APPENDIX \\ Complete Definitions of the 10 Leadership Strategies}

Authoritative. The leader immediately takes charge of a situation, asserts his/her position, gives direct orders/ commands without adequate reason for adopting a course of action, which seems to be based on instinct/gut feel. A leader may also simply adopt regulations and pass down orders. Examples include (1) ordering the soldiers to do a task, (2) taking charge of a situation, with no rationale other than "because I say so," (3) citing field manuals as rationale, and (4) using a commanding officer's order as rationale for a decision.

Avoidance. The leader takes no immediate action to deal with a situation that is clearly his or her responsibility, assuming that if left alone, the situation will resolve itself.

Influencing. The leader convinces or persuades others of his point of view. Examples include (1) discussing issues with the leader's commanding officer so that he or she sees the individual's point of view and (2) convincing other, respected members of the platoon of the leader's position.

Planned action. The leader carefully and deliberately plans the steps taken to execute a course of action and considers options and consequences. Thus, actions tend to be procedural in nature, underscoring the leader's rational thought process. Examples include (1) methodically planning training sessions to achieve a goal and (2) carefully reviewing all aspects of a situation before making a decision.

Proactive. The leader does not wait to be told what to do, anticipates what needs to be done, and does it. Examples include (1) offering to take care of specific tasks for the leader's commanding officer before he or she asks and (2) telling soldiers what to expect so they can plan ahead.

Professional development. The leader focuses on the professional development of his or her soldiers as individuals and as part of the platoon, actively works to build credibility with soldiers and to develop soldiers into a cohesive unit. Encompasses working one on one with a soldier to aid his or her development, providing appropriate training/development activities for each member of the unit. In addition, the leader maintains personal control and military bearing and works on areas of personal development and self-management. Overall, the leader looks at feedback as a method of improving performance. The leader follows through on what he or she says he or she will do and listens frequently to soldiers' opinions and suggestions, particularly in areas outside the platoon leader's expertise. Examples include (1) maintaining respect for self and others, (2) practicing techniques to control inappropriate emotional responses (yelling), and (3) reminding self of short- and long-term goals.

Punishing. The leader threatens soldiers with punitive actions as an immediate response to a situation. Examples include (1) chewing someone out, (2) yelling at soldiers, and (3) threatening them with discharge or other punishment.

Reinforcement. The leader actively seeks out the opinions and advice of key individuals, either inside or outside of his or her direct chain of command, including superior officers, key subordinates, other platoon leaders, and nonmilitary individuals. Examples include (1) using fellow platoon leaders as a feedback group, (2) using competent officers as mentors and sources of advice, (3) asking the company commander for advice on handling a situation, and (4) working through the NCO chain of command to resolve a situation.

Seek additional information. The leader seeks additional information about the current situation. Examples include (1) querying platoon sergeant or soldiers involved in the situation for more information and (2) confirming the current status and looking for underlying causes.

Supportive. The leader seeks to see things from his or her soldiers' perspective, has empathy for soldiers' situation, ensures that soldiers receive appropriate rewards and recognition, and stands up for soldiers when necessary. Examples include (1) arranging for better assignments after difficult ones have been completed and (2) recognizing when the leader's soldiers have reached their limits and doing something about it.

(Manuscript received April 13, 2004;

revision accepted for publication December 1, 2004.) 